\title{
Catalytic conversion of dimethyl ether into propylene over MCM-68 zeolite
}

Sungsik Park, Yasuhiro Watanabe, Yuji Nishita, Takuya Fukuoka, Satoshi Inagaki, and Yoshihiro Kubota*

Division of Materials Science and Chemical Engineering, Yokohama National University, 79-5 Tokiwadai, Hodogaya-ku, Yokohama 240-8501, Japan

*Tel/Fax: +81-45-339-3941, E-mail: kubota@ynu.ac.jp (Y.K.)

\begin{abstract}
Control of the acid site distribution on MCM-68 zeolite catalysts can be achieved by the acid-treatment with nitric acid. Less coke is deposited during DTO reactions over dealuminated MCM-68 compared to the parent MCM-68 probably due to the selective removal of acid sites on the external surface of the parent MCM-68. The higher yields of propylene and butylenes are obtained with lower selectivity for ethylene and lower paraffins over dealuminated MCM-68, whereas ethylene and lower paraffins are predominant over parent MCM-68. The acid-treatment may preferentially remove the strong acid sites, and thus the retained acid sites with moderate strength mainly convert dimethyl ether into propylene and butylenes with high propylene/ethylene (P/E) molar ratio. Besides the issue of high $\mathrm{P} / \mathrm{E}$ ratio, the ratio is also widely controllable by changing the reaction temperature.
\end{abstract}

Keywords: dimethyl ether; propylene; MSE zeolite; catalyst; DTO reaction 


\section{Introduction}

Propylene serves as an essential feedstock for the production of important petrochemicals. Worldwide, the demand for propylene has been steadily increasing and is expected to increase in the future. Currently, worldwide propylene production comes from steam cracking, refinery fluid catalytic cracking (FCC), and other deliberate processes such as propane dehydrogenation, and metathesis. Although steam cracking of naphtha is still a major process for the production of propylene as a co-product of ethylene production, the yield of propylene is low and the propylene-to-ethylene $(\mathrm{P} / \mathrm{E})$ ratio obtained in steam cracking process cannot be tuned due to the thermodynamic reasons. As the demand of propylene is increasing currently and in the future, an increase in propylene production in FCC units has been attempted by optimizing catalysts and operating conditions. Due to the fact that demand growth rates for propylene are exceeding those for ethylene, alternative processes for the production of propylene are necessary [1].

Recently, shale gas development caused a significant increase in the supply of natural gas, especially in the United States [2]. Since global development of shale gas resources has contributed to a decline in natural gas prices, methanol and dimethyl ether, which are derived from natural gas, are considered as an alternative platform chemical. For instance, dimethyl ether can be selectively converted into propylene over zeolite catalysts in the DTO reaction. This non-petroleum based process has received much attention for the production of propylene [3].

For over 30 years, the actual mechanism of the DTO reaction over zeolite catalysts has been the issue for debate. The "hydrocarbon pool mechanism" is believed as a mechanism of the steady state of the DTO reaction [4-9] while possible direct mechanisms, in which dimethyl ether is converted over zeolite catalysts to form the olefins, have been supported by observation of surface species on the zeolite catalysts (infrared spectroscopy) and gas chromatography-mass spectroscopy (GC-MS) analysis of products $[10,11]$.

In hydrocarbon pool mechanism, two catalytic cycles are at work: one in which olefins are repeatedly methylated to form higher olefins which are susceptible to cracking to form light olefins and the other in which aromatics are repeatedly methylated and dealkylated to form light olefins. In the latter case, the formation of light olefins from aromatics is explained by side-chain methylation mechanism and paring reaction mechanism. Both mechanisms suggest the production of propylene in DTO reactions by splitting off of alkyl side-chain; however, the former suggests the alkyl 
side-chain growth by simple side-chain methylation, and the latter suggests growth of alkyl side-chain by ring expansion/contraction leading to a carbon atom interchange between the ring and the substituents $[8,9,12,13]$. It is also reported that the relative propagation of aromatics and olefins-based cycles in DTO mechanism is greatly influenced by the zeolite structure [14]. For instance, aromatics based hydrocarbon pool mechanism is more important in MTO or DTO reactions over SAPO-34 molecular sieve (CHA topology) with the supercage which is enough large to accommodate aromatics [13-16], while methanol conversion catalyzed by ZSM-5 zeolite (MFI topology) both followed the hydrocarbon pool mechanism and the olefin methylation-cracking route $[9,15]$.

SAPO-34 and ZSM-5 have been widely studied to understand not only the reaction mechanism of MTO and DTO reactions but also the role of acid sites and reaction conditions on product distributions. SAPO-34 molecular sieves employed in MTO and DTO reactions as a catalyst has been known to be selective for the formation of lower olefins. The small pore entrances of SAPO-34 molecular sieves allow only the diffusion of linear hydrocarbons. In addition, the cage shape and the cage size of SAPO-34 molecular sieves have been found suitable to preserve reactive intermediates that produce selectively lower olefins [13-17].

An increase in the propylene yield over ZSM-5 by optimizing Si/Al molar ratios [7], control and by phosphorous modification of ZSM-5 [18] was reported. The optimization of Si/Al molar ratios leads ZSM-5 with sufficient acid sites for the propylene production in DTO reactions and phosphorous modification decrease the amount of acid sites with strong acidity. Thus, a decrease in the amount of acid sites with strong acidity limits further consecutive reactions of the lower olefins, resulting in a high selectivity to lower olefins in DTO reactions. Although ZSM-5 is regarded as a reasonable catalyst in the production of propylene, low P/E molar ratio needs to be improved in DTO reactions. This situation prompted us to the investigation of new catalysts that can selectively convert dimethyl ether into propylene with high P/E molar ratio in DTO reactions.

Beta zeolite, on the other hand, has relatively large pores in comparison with ZSM-5. Under the same reaction conditions, reaction catalyzed by beta results in seven times higher P/E ratio (C-\%) compared to ZSM-5 with similar Si/Al ratio. The reactions catalyzed by ZSM-5 and beta mainly produce propylene. The low ethylene yield over beta was explained by observation of reaction intermediates occluded in the spent catalysts. Over zeolite beta catalyst, the large amount of penta- 
and hexamethylbenzene was observed while di- and trimethylbenzenes were the dominant aromatic intermediates over ZSM-5. Reported study [8] insisted that the difference in distribution of reaction intermediates is due to steric constraints imposed by the framework of zeolite beta and ZSM-5. The narrow channels on ZSM-5 lead to the formation of the lower methylbenzene intermediates that favor the formation of ethylene, thus resulting in a relatively high ethylene production over ZSM-5, although other factors, such as strength of acid sites on zeolite catalysts should also play an important role. Even though P/E ratio (C-\%) over beta was higher than that obtained over ZSM-5, the propylene selectivity was higher over ZSM-5. However the experimental results indicate that it is possible to directly improve the yield of propylene with high $\mathrm{P} / \mathrm{E}$ ratios in MTO and DTO reaction by the choice of catalysts [8].

Over the past decade, new types of zeolite materials have been synthesized. MCM-68 (MSE topology [19]) zeolite is a new type of three-dimensional zeolite with $12 \times 10 \times 10 \mathrm{R}$ channel system. The zeolite has a characteristic structure in which a $12 \mathrm{R}$ straight channel intersects with two independent tortuous $10 \mathrm{R}$ channels and possesses a supercage $(18 \mathrm{R} \times 12 \mathrm{R})$, which is accessible only through 10R windows [20]. The features of the MCM-68 zeolite are attracting attention, because there are only a handful of acidic zeolites that contain three-dimensional channel systems with large pores. Since its discovery in 2000 by Mobil researchers [21], the interest in the MCM-68 zeolite has been growing owing to its promising catalytic properties in reactions such as alkylation of biphenyl [22] or naphthalene [23] and cracking of hexane [24,25]. Other applications as alkylation catalysts [26], oxidation catalysts [27] and hydrocarbon traps [28] have been independently reported. In hexane cracking, the propylene selectivity is higher over MCM-68 than over ZSM-5 [24,25]. The catalytic properties of MCM-68 in hexane cracking as well as the existence of large pore and the controllable $\mathrm{Si} / \mathrm{Al}$ molar ratio in MCM-68 suggest that MCM-68 can be used to obtain a high P/E ratio in the dimethyl ether conversion.

In this work, we investigate the DTO reactions over MCM-68 with various Si/Al molar ratios to elucidate the effect of the density and distribution of acid sites on the product selectivity, product yields and durability to coke formation. Moreover, the change in product selectivity for the lower olefins on MCM-68 with various $\mathrm{Si} / \mathrm{Al}$ molar ratios is interpreted in terms of pore structures and the distribution of acid sites. Since the strength of acid sites can vary due to the impact of geometry on acid sites, the acid strength can vary for zeolites having same structure. Therefore, the study on the relative strength of acid sites on MCM-68 and 
dealuminated MCM-68 is significant for understanding the relationship between their acid properties and catalytic performances in DTO reaction. In order to acquire information on the relative strength of Brønsted and Lewis acid sites on MCM-68 and dealuminated MCM-68, the interaction of pyridine with the acid sites on MCM-68 was studied at various temperatures. Finally, the influence of temperature on propylene yields and P/E molar ratios is investigated.

\section{Experimental}

\subsection{Materials}

Commercially available ZSM-5 zeolite catalyst (CBV28014, Si/Al = 153, Zeolyst International) was used in this study. MCM-68 zeolite was hydrothermally synthesized according to the reported procedure [20-29]. A typical procedure is as follows. Colloidal silica (Ludox HS-40, DuPont, $40 \mathrm{wt} \% \mathrm{SiO}_{2}$ ), de-ionized water and $\mathrm{Al}(\mathrm{OH})_{3}\left(\mathrm{Pfaltz} \&\right.$ Bauer) were mixed for $10 \mathrm{~min}$. Aqueous $\mathrm{KOH}$ solution $\left(5.93 \mathrm{mmol} \mathrm{g} \mathrm{g}^{-1}\right)$ was added to the solution, and stirred for further $30 \mathrm{~min}$. Then, $N, N, N^{\prime}, N^{\prime}$-tetraethylbicyclo[2.2.2] oct-7-ene-2,3:5,6dipyrrolidinium diiodide (TEBOP $\left.{ }^{2+}\left(\mathrm{I}^{-}\right)_{2}\right)$ was added as a structure-directing agent (SDA), and the mixture was stirred for another $4 \mathrm{~h}$. The resulting mixture with a molar composition $1.0 \mathrm{SiO}_{2}-0.1 \mathrm{TEBOP}^{2+}\left(\mathrm{I}^{-}\right)_{2}-$ $0.375 \mathrm{KOH}-0.1 \mathrm{Al}(\mathrm{OH})_{3}-30 \mathrm{H}_{2} \mathrm{O}$ was taken into a Teflon-lined autoclave, and kept statically at $160{ }^{\circ} \mathrm{C}$ for $16 \mathrm{~d}$ in a convection oven. After quenching the autoclave in an ice bath for $30 \mathrm{~min}$, the solid part was separated by centrifugation, washed several times with de-ionized water, and dried overnight at $100{ }^{\circ} \mathrm{C}$. The as-synthesized MCM-68 zeolite was calcined at $650{ }^{\circ} \mathrm{C}$ for $10 \mathrm{~h}$ to eliminate SDA.

$\mathrm{NH}_{4}$-forms of MCM-68 were prepared by an ion-exchange process using $\mathrm{NH}_{4} \mathrm{NO}_{3}$ solution. A particular procedure in this work was as follows: $\mathrm{NH}_{4} \mathrm{NO}_{3}(4.0 \mathrm{~g})$ and the calcined MCM-68 sample $(0.6 \mathrm{~g})$ were mixed with $\mathrm{H}_{2} \mathrm{O}(60 \mathrm{~mL})$ in a 250 -mL polypropylene bottle. The bottle was capped tightly and allowed to stand at $80{ }^{\circ} \mathrm{C}$ for $24 \mathrm{~h}$ with occasional purge of pressure and careful shaking. After cooling down, the sample was separated by filtration, and washed with de-ionized water. This process was repeated twice. The sample was filtered, washed thoroughly with water, and dried overnight in an oven at $100{ }^{\circ} \mathrm{C}$. Then, the resulting zeolite was again calcined in a muffle furnace. The temperature was raised from room temperature to $650{ }^{\circ} \mathrm{C}$ over a period of $10.5 \mathrm{~h}$, and kept at the same temperature for $10 \mathrm{~h}$ to give MCM-68 in $\mathrm{H}^{+}$-form $(\mathrm{Si} / \mathrm{Al}=$ ca. 10$)$.

Calcined MCM-68 samples (i.e. the (K, H)-form samples just after removal of SDA by calcination) were used to prepare $\mathrm{H}$-forms of MCM-68 with various $\mathrm{Si} / \mathrm{Al}$ molar ratios by dealumination, which was carried 
out by treating with $1-10 \mathrm{~mol} \mathrm{~L}^{-1} \mathrm{HNO}_{3}$ solution $\left(30 \mathrm{~mL}(\mathrm{~g} \text {-sample })^{-1}\right)$ in a $200-\mathrm{mL}$ round-bottom flask immersed in an oil bath $\left(80^{\circ} \mathrm{C}\right)$ for $2 \mathrm{~h}$. The dealuminated samples were recovered upon filtration followed by washing with de-ionized water and drying in an oven at $100^{\circ} \mathrm{C}$. These samples were labeled as MCM-68(x), where $x$ denotes the Si/Al molar ratios determined by ICP analysis, and used as catalysts without further calcinations.

\subsection{Characterization}

Crystal structures of the obtained solid products were determined by X-ray powder diffraction (XRD) on an Ultima IV (Rigaku) using $\mathrm{CuK} \alpha$ radiation at $40 \mathrm{kV}$ and $20 \mathrm{~mA}$. The textural properties of the catalysts were calculated by a multipoint $\mathrm{N}_{2}$ adsorption-desorption method at $-196{ }^{\circ} \mathrm{C}$ with an Autosorb-iQ analyzer (Quantachrome Instruments). Micropore volumes of the catalysts were calculated from the adsorption isotherm by the $t$-plot method. Specific surface areas of the catalysts were calculated from the adsorption isotherm by the Brunauer-Emmett-Teller (BET) equation. For a surface area evaluation, data in the relative pressure range of $0.05-0.10$ are used. The chemical compositions of zeolites were determined by using inductively coupled plasma spectrometer (ICP, ICP-8000E, Shimadzu). The number of acid sites was measured by ammonia temperature-programmed desorption $\left(\mathrm{NH}_{3}\right.$-TPD) measurement on a BELCAT-B (Japan Bel Inc.) with a thermal conductivity detector (TCD). The catalyst was preheated at $600{ }^{\circ} \mathrm{C}$ prior to the measurement under He flow. The TPD data were collected at a ramping rate of $10{ }^{\circ} \mathrm{C} \mathrm{min}{ }^{-1}$. The number of acid sites was determined from the area of $h$-peak [30] in their profiles. The shape and the particle size of the MCM-68 zeolites were examined by a scanning electron microscope (JSM-7001F, JEOL). The coke contents of the used catalysts were determined in a thermogravimetirc analyzer (TG-8120, Rigaku). The temperature was raised from room temperature to $800{ }^{\circ} \mathrm{C}$ with the rate of $10{ }^{\circ} \mathrm{C} \mathrm{min}^{-1}$ under air flow $(30$ $\mathrm{cm}^{3}$ (N.T.P.) $\mathrm{min}^{-1}$ ). The weight loss observed from 300 to $700{ }^{\circ} \mathrm{C}$ was ascribed to coke. For FT-IR spectroscopy analysis, empty cell was vacuumed $\left(p<10^{-5}\right.$ torr) and the spectrum was recorded as reference using a JASCO FT/IR-6100 spectrometer equipped with a Hg-Cd-Te (MCT) detector cooled by liquid nitrogen. Self-supporting zeolite wafers (10-20 mg) were suspended between $\mathrm{NaCl}$ windows in a cylindrical cell similar to that described in refs. 10 and 11 . The sample was then heated to $500{ }^{\circ} \mathrm{C}$ at a ramping rate of 5 ${ }^{\circ} \mathrm{C} \min ^{-1}$ under vacuum, held for $1 \mathrm{~h}$, and cooled to $100{ }^{\circ} \mathrm{C}$ prior to the adsorption experiments. Pyridine (ca. $2.7 \mathrm{kPa}$ ) was injected into the cell. The cell was left in vacuum for $10 \mathrm{~min}$ to allow physically adsorbed pyridine to desorb. Spectra were then recorded and averaged over 64 scans between 1250 and $4000 \mathrm{~cm}^{-1}$ 
with $4 \mathrm{~cm}^{-1}$ resolution. The temperature of the IR cell was progressively increased from 100 to $450{ }^{\circ} \mathrm{C}$ and the spectrum was recorded at $150,200,250,300,350,400$, and $450{ }^{\circ} \mathrm{C}$. The spectrum was recorded at least two times at each temperature (5-minute interval). Peak areas corresponding to pyridine adsorbed at Brønsted $\left(1545 \mathrm{~cm}^{-1}\right)$ and Lewis $\left(1450 \mathrm{~cm}^{-1}\right)$ acid sites were used for the comparison of relative strength of acid sites on MCM-68.

\subsection{Catalytic reactions}

Dimethyl ether (partial pressure: $4.9 \mathrm{kPa}$ ) was introduced into the top of the reactor (a down-flow quartz-tube microreactor with a 9-mm inner-diameter) with $\mathrm{He}\left(40 \mathrm{~cm}^{3}\right.$ (N.T.P) $\left.\mathrm{min}^{-1}\right)$ (see Fig. S1). Each zeolite catalyst was pelletized without any binder, roughly crushed and then sieved to obtain catalyst pellets with 500-600 $\mu \mathrm{m}$ in size. Prior to running the reaction, $100 \mathrm{mg}$ of catalyst pellets were placed in the fixed bed of the reactor. The temperature of electric furnace was raised to the pretreatment temperature with the rate of $10{ }^{\circ} \mathrm{C} \mathrm{min}^{-1}$ under air flow $\left(40 \mathrm{~cm}^{3}\right.$ (N.T.P.) $\mathrm{min}^{-1}$ ). After pretreatment at $550{ }^{\circ} \mathrm{C}$ for $1 \mathrm{~h}$, the temperature was adjusted to reaction temperature under He flow $\left(40 \mathrm{~cm}^{3}\right.$ (N.T.P. $\left.) \mathrm{min}^{-1}\right)$. The DTO reaction started when dimethyl ether was introduced into reactor. The reactants and products were analyzed on DB-5 capillary column (i.d. $0.53 \mathrm{~mm}$; length $60 \mathrm{~m}$; thickness of the stationary phase $5.00 \mu \mathrm{m}$; Agilent Technology) and an HP-PLOT/Q capillary column (i.d. $0.53 \mathrm{~mm}$; length $30 \mathrm{~m}$; thickness of the stationary phase $40.0 \mu \mathrm{m}$; Agilent Technology) using a GC-14B (Shimadzu) with a flame ionization detector (FID). The conversion of dimethyl ether, the selectivity of the products, the yield of the products and material balance were calculated on the carbon-basis of the initial amount of dimethyl ether.

The cracking of cumene or 1,3,5-triisopropylbenzene (TIPB) was performed at $300{ }^{\circ} \mathrm{C}$ under atmospheric pressure in a pulse-type quartz-tube (i.d. $4 \mathrm{~mm})$ microreactor (see Fig. S2) under a stream of helium $\left(30 \mathrm{~cm}^{3}\right.$ (N.T.P.) $\min ^{-1}$ ). The catalyst amount, dose amounts of cumene and TIPB are $20 \mathrm{mg}, 0.8 \mu \mathrm{L}$, and $0.6 \mu \mathrm{L}$, respectively. The products were analyzed by TCD on GC equipped with stainless steel column (i.d. $3.0 \mathrm{~mm}$; length $6.0 \mathrm{~m})$ packed with Silicone OV-1 (60-80 mesh).

\section{Results and discussion}

\subsection{Physicochemical properties of MCM-68 zeolites prepared in this study}

The MCM-68 zeolites with high Si/Al molar ratios are prepared by treating the parent MCM-68(10) with acid solution to remove framework aluminum species. The XRD patterns of ion-exchanged MCM-68 and 
XRD patterns of dealuminated MCM-68 are shown in Fig. 1. Dealuminated MCM-68 maintains the MSE framework after acid treatment indicating that the framework of MCM-68 was quite stable against acid treatment. As shown in SEM images in Fig. 2, the particle size of ion-exchanged MCM-68 zeolites was about $100 \mathrm{~nm}$ and no change in morphology and particle size was observed. The $\mathrm{N}_{2}$ adsorption-desorption of MCM-68 gave a typical reversible type I isotherms (see Fig. S3), and the surface areas and pore volumes calculated on the basis of the isotherms are listed in Table 1. As shown in Table 1, their BET surface areas and micropore volumes were quite similar before and after acid treatments (BET surface areas; 490-560 $\mathrm{m}^{2}$ $(\mathrm{g} \text {-catalyst })^{-1}$, micropore volume; $\left.0.181-0.188 \mathrm{~cm}^{3}(\mathrm{~g} \text {-catalyst })^{-1}\right)$, indicating that the dealumination process did not induce porosity changes in MCM-68. The number of acid sites estimated from the so-called $h$-peak [30] on the $\mathrm{NH}_{3}$-TPD profiles (see Fig. S4) are also listed in Table 1. The use of nitric acid with higher concentrations gave the MCM-68 with the larger $\mathrm{Si} / \mathrm{Al}$ ratios as well as the smaller number of acid sites (Table 1). Since the MCM-68 with different Si/Al ratios showed no significant differences in their XRD patterns, SEM images and $\mathrm{N}_{2}$ adsorption isotherms, their physical properties such as framework and pore structures are similar except the amount of acid sites. The controllable Si/Al molar ratio of MCM-68 and thus changes in their catalytic performance, while keeping its framework structure, is one of the interesting characteristics as a solid acid catalyst.

\subsection{The catalytic cracking of 1,3,5-triisopropylbenzene and cumene on MCM-68 zeolites}

Acid catalyzed reactions, such as a cracking of bulky molecules which are larger than the pore-entrance, give useful information to evaluate the reactivity of acid sites at external surface [25,31-34]. The results of the cracking of TIPB and cumene over parent MCM-68(10) and dealuminated MCM-68(167) are summarized in Fig. 3. Catalytic cracking of TIPB occurs only at acid sites on the external surface of MCM-68, as TIPB molecules are much larger than the pore diameters of the $12 \mathrm{R}$ and 10R micropores within the MSE framework. In contrast, cumene molecules, which are much smaller than TIPB molecules, can penetrate the 10R micropores in the MSE framework. Catalytic cracking of cumene thus evaluates the acid sites on both the external and internal surfaces of MCM-68 catalysts [25]. The parent MCM-68(10) has high activity for both TIPB and cumene cracking reactions. In contrast, the conversion of TIPB cracking reaction catalyzed by dealuminated MCM-68(167) was low as compared with that catalyzed by parent MCM-68(10) and it was deactivated after two pulses of TIPB. Despite the low catalytic activity of MCM-68(167) in TIPB cracking reaction, it showed high catalytic activity in cumene cracking reaction (Fig. 3). These results 
indicate that the acid sites on the internal surface were retained after acid-treatment, while the framework $\mathrm{Al}$ on the external surface is removed.

\subsection{FT-IR spectroscopy analysis of pyridine adsorbed on MCM-68 at various temperatures}

The IR spectra of pyridine adsorbed on parent MCM-68(10) and dealuminated MCM-68(47) at cell temperature of $150,200,250,300,350,400$, and $450{ }^{\circ} \mathrm{C}$ are presented in Fig. 4. The peak intensities of pyridine interact with acid sites on both MCM-68(10) and MCM-68(47) slightly decreased as temperature increased; however, pyridine bonded to Brønsted (B) and Lewis (L) acid sites on MCM-68(10) are present even at high cell temperature. On the other hand, the peak intensities of pyridine interact with acid sites on dealuminated MCM-68(47) were readily decreased even at low cell temperature. The relative peak area of pyridine adsorbed on Brønsted and Lewis acid sites as a function of cell temperatures are shown in Fig. 5. The filled symbols are obtained from the spectrum of parent MCM-68(10) and open symbols are obtained from the spectrum of dealuminated MCM-68(47). The relative peak area of pyridine adsorbed on Brønsted and Lewis acid sites were measured using the following equation: Relative peak area $=[\mathrm{peak}$ area at observed cell temperature]/[peak area at $\left.150{ }^{\circ} \mathrm{C}\right]$. The tendency that can be seen in Fig. 5 tells that both the Brønsted and Lewis acid sites on parent MCM-68(10) are sufficiently strong to retain adsorbed pyridine even after outgassing at high temperature while pyridine adsorbed on dealuminated MCM-68(47) were easily removed with the increase in cell temperature. These results suggest that the stronger Brønsted and Lewis acid sites on parent MCM-68(10) were more easily removed by acid-treatment (Fig. 5).

\subsection{DTO reactions catalyzed by MCM-68 zeolites with various Si/Al molar ratios}

The conversion of dimethyl ether over the MCM-68 zeolites is quite dependent on the contact time of dimethyl ether (Fig. S5). In order to evaluate the catalytic performance of entire acid sites on MCM-68, the contact time of dimethyl ether was fixed as $\mathrm{W} / \mathrm{F}=20.0 \mathrm{~g} \mathrm{~h} \mathrm{~mol}^{-1}$ to achieve high dimethyl ether conversion of around $95 \%$ for the comparison of product yields over different catalysts.

The results of the DTO reactions on MCM-68 with the various Si/Al molar ratios are listed in Table 2. Under the same reaction conditions, the conversion of dimethyl ether was high over the ion-exchanged MCM-68 zeolite and it decreased as the Si/Al ratio increased. The combined yields of methane, ethane, and propane (denoted as $\mathrm{C} 1+\mathrm{C} 2+\mathrm{C} 3$ ) as well as the yields of $\mathrm{C} 4$ paraffins (denoted as $\mathrm{C} 4)$ and ethylene (denoted as $\mathrm{C} 2=$ ) decreased as the $\mathrm{Si} / \mathrm{Al}$ molar ratio of MCM-68 increased. The yields of aromatics over the 
MCM-68(10) zeolite was relatively lower than that over MCM-68(134) which may be due to coke formed from aromatics during the DTO reaction. When catalyzed by MCM-68(134), which possesses a small amount of acid sites in comparison with parent MCM-68(10), propylene and butylenes were the major products (C-\% yields are displayed in the Table 2), whereas the product yields towards higher-carbon number products and paraffins decreased. Propylene and butylenes could be consumed to form olefins with a higher carbon number and aromatics and paraffins are produced through the cyclization and hydrogen transfer reactions. It is believed that a high density of acid site on MCM-68 is responsible for the formation of paraffins, higher alkenes and aromatics by the consecutive reactions. By dealumination of parent MCM-68 (K-form), the acid sites existing on the external surface and/or pore mouth were selectively removed, while those on the internal surface were retained. The removal of acid sites on the external surface and pore mouth may suppress the reactions that convert light olefins into higher olefins or aromatics. This could explain the decreased yields of hydrocarbons with a carbon number more than 6 and aromatics (Table 2). Despite the results of TIPB and cumene cracking reactions indicate that the retained acid sites after acid-treatment mainly distributed on the internal surface of MCM-68, the detailed information on the location of the acid sites, whether they are located inside 12R or 10R pores, was not clear.

In catalysis over zeolites, pore size and pore volume [35] of zeolites significantly affect product selectivity, thus the observation of the product distribution and product selectivity may alter the information on the location of the acid sites. Previously, we compared the catalytic performance of MCM-68 with ZSM-5, mordenite and beta zeolite in hexane cracking [24,25]. The product distributions over dealuminated MCM-68 were more like that over ZSM-5, while product distributions over parent MCM-68 were more like that over mordenite and beta zeolite. In this study, catalytic performance of MCM-68 was compared with that of ZSM-5. Despite the lower yields of ethylene and aromatics, product distributions in DTO reaction over MCM-68(159) are quite similar to that catalyzed by ZSM-5(153) (Table 2). Since ZSM-5 is composed of $10 \mathrm{R}$ pore systems, light olefins are mainly produced from DME due to the narrow pore windows. The similar product distributions between ZSM-5(153) and MCM-68(159) may indicate that the acid sites on MCM-68(159) are mainly distributed inside the supercage which is only accessible through 10R. It has recently been shown that the higher methylbenzenes in beta zeolite give a high selectivity to propylene and butylenes, while the lower methylbenzene analogues in ZSM-5 give a high selectivity to ethylene and propylene [8]. The large pore system in beta zeolite accommodated higher methylbenzenes, thus subtle difference in reaction intermediates may change product distributions. By referring this information, we 
speculate that propylene and butylenes are mainly produced over MCM-68 through the aromatics related to hydrocarbon pool mechanism inside the supercage or intersection of the straight $12 \mathrm{R}$ channel and $10 \mathrm{R}$ channels which are large enough for bulky reaction intermediates to be formed.

The removal of the stronger Lewis acid sites (Fig. 4 and Fig. 5) responsible for the hydrogen transfer reaction is believed to decrease the yields of paraffins in DTO reactions over properly dealuminated MCM-68. The outstanding point in the variation of the product yields in the DTO reactions over dealuminated MCM-68 is the increases in the yields of lower olefins such as propylene and butylenes, but not ethylene. The yield of ethylene over parent MCM-68 was high (6.5 C-\%), while that over dealuminated MCM-68 zeolite was as low as $1.0 \mathrm{C}-\%$. From the viewpoint of intrinsic acid strength, the formation of ethylene will preferentially proceed by stronger acid site as compared to the formation of propylene. At the same time, dealumination of MCM-68 could realize the catalysts having acid site distribution producing more propylene and less ethylene, probably due to the selective removal of the stronger Brønsted acid sites producing ethylene. According to the results in Table 2, it is recognized that the amount of acid site and the location of the acid site play a key role in controlling product distribution, despite the moderate strength of acid site of dealuminated MCM-68, as compared to that of parent MCM-68, which would be the primary reason for the high $\mathrm{P} / \mathrm{E}$ molar ratio in DTO reactions.

\subsection{The thermogravimetric analysis of the spent catalysts}

The thermogravimetric analysis of the MCM-68 zeolite used in the DTO reaction for 305 min indicates a considerable variance in the amount of polymerized compounds and coke deposited on the spent catalyst.

The weight loss in the used MCM-68(10) was as large as 65 mg-coke (g-cat) ${ }^{-1}$ (Table 2), whereas the weight losses in the used MCM-68 with higher Si/Al molar ratios were much smaller than that of MCM-68(10) (from $<1 / 3$ to $2 / 3$ levels). The fact that dealuminated MCM-68 with a lower density of acid sites caused a reduction in coke formation during DTO reaction as compared to Al-rich MCM-68(10) with a high density of acid sites are reasonable.

\subsection{Comparison of product selectivity over MCM-68 zeolites with various Si/Al molar ratios}

In order to obtain similar DME conversion levels, we evaluated the effect of contact-time on DME conversion. Fig.S5 shows the conversion of DME in terms of contact time. Catalytic results listed in Table 3 were carefully chosen among the data obtained over MCM-68 at the different space time. For instance, 
MCM-68(69) gave the meaningful level of DME conversion (almost $99 \%$ ) which is comparable in product selectivity when W/F was $10 \mathrm{~g} \mathrm{~h} \mathrm{~mol}^{-1}$. Other two catalysts, MCM-68(134) and MCM-68(167) gave DME conversion around $99 \%$ at the contact time of 25 and $30 \mathrm{~g} \mathrm{~h} \mathrm{~mol}^{-1}$, respectively, thus it is reasonable to compare the product selectivity of MCM-68 listed in Table 3. The changes of product distributions in terms of time-on-stream (TOS) were not noticeable except MCM-68(69), in which product distributions slightly change with time-on-stream probably due to coke deposition during DTO reaction (Fig. S6).

The selectivity of methane, ethane and propane (denoted as $\mathrm{C} 1+\mathrm{C} 2+\mathrm{C} 3$ ), as well as and $\mathrm{C} 4$ paraffins (denoted as $\mathrm{C} 4$ ) and ethylene decreased with the increase in $\mathrm{Si} / \mathrm{Al}$ molar ratios of MCM-68. The selectivity of propylene and butylenes increased as Si/Al molar ratios of MCM-68 increased. The sum of selectivity of propylene and butylenes was as high as 65 C-\% over MCM-68(167), while that over MCM-68(69) was 43 C-\%. The selectivity of ethylene over MCM-68(69) was as high as 4.2 C-\%, whereas that over MCM-68(167) was as low as 1.4 C-\%. With DME conversion at around $99 \%$, the highest selectivity to propylene and butylenes (40 C-\% and 25 C-\%, respectively) was obtained over MCM-68(167). When catalyzed by MCM-68(167), which possesses a small amount of acid sites than MCM-68(69), propylene and butylenes were the major products with negligible content of higher-carbon number products and ethylene. The dealuminated MCM-68(167) zeolite, which contains 1 or less aluminum atom per a unit cell showed increased propylene selectivity with decreased ethylene selectivity. Based on these results, we speculate that the formation of propylene over properly dealuminated MCM-68 zeolites takes place inside the pore system, especially inside the supercage $(18 \mathrm{R} \times 12 \mathrm{R})$ which is large enough for bulky reaction intermediates to form. These polymethylbenzenes would be further methylated to isopropylbenzene derivatives and propylene would be produced by the elimination of isopropyl side chain from the aromatic ring in the intermediates. Although 10R windows of MCM-68 impede the diffusion of aromatics, relatively wide 12R window allow the diffusion of aromatics in DTO reaction. By observing the higher selectivity of aromatics and products with a higher carbon number over MCM-68(69) and the lower selectivity of aromatics and products with a higher carbon number over MCM-68(134) and MCM-68(167), we speculate that MCM-68(69) may possess more acid sites in 12R pore system in comparison with MCM-68(134) and MCM-68(167).

The P/E ratio in the product over MCM-68(167) was as high as 30 and the sum of the selectivity of propylene and butylenes was 65 C-\%. When catalyzed by ZSM-5(153), the sum of the selectivity of propylene and butylenes was $45 \mathrm{C}-\%$ and the $\mathrm{P} / \mathrm{E}$ ratio in product composition was only 8 . These results indicate that the properly dealuminated MCM-68 selectively produce propylene and butylenes with high P/E 
ratio as compared to ZSM-5 at the similar dimethyl ether conversion level.

\subsection{Effect of reaction temperature on the product distribution}

The distribution of product yields in DTO reaction at different reaction temperatures was investigated. At the reaction temperature from 400 to $500{ }^{\circ} \mathrm{C}$, DTO reactions were conducted on MCM-68(159) and ZSM-5(153) (Fig. 6). The DME conversion increased as reaction temperature increased from 400 to $500{ }^{\circ} \mathrm{C}$. The yields of products having carbon number greater than 5 dropped with the increase in reaction temperature from 400 to $500{ }^{\circ} \mathrm{C}$, whereas the propylene yield increased from 30 to $41 \mathrm{C}-\%$. The yield of aromatics and paraffins $(\mathrm{C} 1+\mathrm{C} 2+\mathrm{C} 3$ and $\mathrm{C} 4)$ also increased with increasing of reaction temperature, probably due to the extended hydrogen transfer reaction and aromatization at the increased reaction temperature. Although the yields of propylene increased with increasing the reaction temperature, the P/E ratios in the DTO reactions on MCM-68(159) zeolite decreased due to the increased yields of ethylene. Nevertheless, the comparison between the reactions over ZSM-5(153) and MCM-68(159) at 400 and $500{ }^{\circ} \mathrm{C}$ showed that the P/E molar ratio was higher over MCM-68(159) than that over ZSM-5 (Fig. 7). The results indicates that the P/E ratio can be widely controlled to supply more propylene with less ethylene by optimizing not only S/Al molar ratio but also reaction temperature over dealuminated MCM-68.

\section{Conclusions}

Tuning the acid site distribution in MCM-68 zeolite catalysts was achieved by the post-synthetic acid-treatment by using nitric acid. The dealumination of MCM-68 allowed the selective removal of the external acid sites with a decrease in the $\mathrm{Al}$ content, proven by the unique behavior in the cracking of TIPB or cumene over dealuminated MCM-68. In the DTO reaction at $400{ }^{\circ} \mathrm{C}$, the higher yields of propylene $(37$ C-\%) and butylenes (22 C-\%) were obtained accompanying with lower yield of ethylene, lower paraffins, and aromatics (1.2, 0.8, and $2.1 \mathrm{C}-\%$, respectively) over dealuminated MCM-68(134), whereas the production of ethylene and aromatics as well as coke deposition were predominant over parent MCM-68(10) (Table 2). Drastic change in the product distributions from parent MCM-68(10) to dealuminated MCM-68(134) is probably due to the remaining acid sites with a moderate acid strength within micropore that mainly cause lower yield of ethylene and a decrease in coke content during DTO reaction. In other words, the dealumination treatment of parent MCM-68 may selectively remove both the stronger Brønsted acid sites to produce ethylene and the Lewis acid sites to cause the hydrogenation/dehydrogenation and 
aromatization of olefins into paraffins and aromatics. Besides extremely high $\mathrm{P} / \mathrm{E}$ molar ratio (greater than 25) obtained in DTO reaction over dealuminated MCM-68 as compared to ZSM-5 with a similar Si/Al molar ratio (P/E molar ratio was ca. 5), the P/E molar ratio in the DTO reaction catalyzed by dealuminated MCM-68 is widely controllable also by changing the reaction temperature from 400 to $500{ }^{\circ} \mathrm{C}$. The finding in this paper suggest that dealuminated MCM-68 catalyst is adoptable in the highly selective production of propylene from dimethyl ether, and the dealumination treatment of zeolite catalysts would design the acid site distribution in the zeolite framework to bring out desirable acid catalytic properties.

\section{Acknowledgements}

This work was financially supported by Adaptable and Seamless Technology Transfer Program through Target-driven R\&D (A-STEP, AS231Z03507C) from Japan Science and Technology Agency (JST). S. I. thanks Arai Science and Technology Foundation.

\section{References}

[1] J.S. Plotkin, Catal. Today 106 (2005) 10-14.

[2] Q. Wang, X. Chen, A. N. Jha, H. Rogers, Renewable and Sustainable Energy Reviews 30 (2014) $1-28$.

[3] F.J. Keil, Micropor. Mesopor. Mater. 29 (1999) 49-66.

[4] M. Stocker, Micropor. Mesopor. Mater. 29 (1999) 3-48.

[5] C.D. Chang, C.T. Chu, R.F. Socha, J. Catal. 86 (1984) 289-296.

[6] C.D. Chang, A.J. Silvestri, J. Catal. 47 (1977) 249-259.

[7] J.Q. Chen, A. Bozzano, B. Glover, T. Fuglerud, S. Kvisle, Catal. Today 106 (2005) 103-107.

[8] M. Bjørgen, F. Joensen, K. Lillerud, U. Olsbye, S. Svelle, Catal. Today 142 (2009) 90-97.

[9] S. Ilias, R. Khare, A. Malek, A. Bhan, J. Catal. 303 (2013) 135-140.

[10] H. Yamazaki, H. Sima, H. Imai, T. Tatsumi, J. N. Kondo, Angew. Chem. Int. Ed. 50 (2011) $1853-1856$.

[11] H. Yamazaki, H. Shima, H. Imai, T. Yokoi, T. Tatsumi, J. N. Kondo, J. Phys. Chem. C 116 (2012) $24091-24097$.

[12] R.F. Sullivan, C.J. Egan, G.E. Langlois, R.P. Sieg, J. Am. Chem. Soc. 83 (1961) 1156-1160.

[13] W. Song, H. Fu, J.F. Haw, J. Am. Chem. Soc. 123 (2001) 4749-4754. 
[14] U. Olsbye, S. Svelle, M. Bjorgen, P. Beato, T.V.W. Janssens, F. Joensen, S. Bordiga, K.P. Lillerud, Angew. Chem. Int. Ed. 51 (2012) 5810-5831.

[15] J. Li, Y. Wei, G. Liu, Y. Qi, P. Tian, B. Li, Y. He, Z. Liu, Catal. Today 171 (2011) 221-228.

[16] J. Park, J. Lee, K. Kim, S. Hong, G. Seo, Appl. Catal. A: General 339 (2008) 36-44.

[17] H. Jang, H. Min, J. Lee, S. Hong, G. Seo, Appl. Catal. A: General 437 (2012) 120-130.

[18] H. Jang, H. Min, J. Lee, S. Hong, G. Seo, J. Catal. 299 (2013) 240-248.

[19] Ch. Baerlocher, L.B. McCusker, D.H. Olson, Atlas of Zeolite Framework Types, Elsevier, Amsterdam, 6th edn. 2007, see also: http://www.iza-structure.org/databases/.

[20] D.L. Dorset, S.C.Weston, S.S. Dhingra, J. Phys. Chem. B 110 (2006) 2045-2050.

[21] D.C. Calabro, J.C. Cheng, R.A. Crane Jr, C.T. Kresge, S.S. Dhingra, M.A. Steckel, D.L. Stern, S.C. Weston, U.S. Patent 6049 018, 2000.

[22] T. Shibata, S. Suzuki, H. Kawagoe, K. Komura, Y. Kubota, Y. Sugi, J.-H. Kim, G. Seo, Micropor. Mesopor. Mater. 116 (2008) 216-226.

[23] T. Shibata, H. Kawagoe, H. Naiki, K. Komura, Y. Kubota, Y. Sugi, J. Mol. Catal. A: Chemical 297 (2009) 80-85.

[24] S. Inagaki, K. Takechi, Y. Kubota, Chem. Commun. 46 (2010) 2662-2664.

[25] Y. Kubota, S. Inagaki, K. Takechi, Catal. Today 226 (2014) 109-116.

[26] S. Ernst, S.P. Elangovan, M. Gerstner, M. Hartmann, S. Sauerbeck, Abstr 14th Int Zeol. Conf. 2004, 982.

[27] Y. Kubota, Y. Koyama, T. Yamada, S. Inagaki, T. Tatsumi, Chem. Commoun. 46 (2008) $6224-6226$.

[28] S.P. Elangovan, M. Ogura, S. Ernst, M. Hartmann, S. Tontisirin, M.E. Davis, T. Okubo, Micropor. Mesopor. Mater. 26 (2006) 210-215.

[29] S. Inagaki, Y. Tsuboi, Y. Nishita, T. Syahylah, T. Wakihara, Y. Kubota., Chem. Eur. J. 19 (2013) $7780-7786$.

[30] M. Niwa, K. Katada, Catal. Surv. Jpn. 1 (1997) 215-226.

[31] Y. Koyama, T. Ikeda, T. Tatsumi, Y. Kubota, Angew. Chem. Int. Ed. 47 (2008) 1042-1046.

[32] S. Namba, A. Inaka, T. Yashima, Zeolites 6 (1986) 107-110.

[33] S. Tawada, Y. Sugi, Y. Kubota, Y. Imada, T. Hanaoka, T. Matsuzaki, K. Nakajima, K. Kunimori, J.-H. Kim, Catal. Today 60 (2000) 243-253. 
[34] S. Inagaki, S. Shinoda, Y. Kaneko, K. Takechi, R. Komatsu, Y. Tsuboi, H. Yamazaki, J. N. Kondo, Y. Kubota, ACS Catal. 3 (2013) 74-78.

[35] T. Koyama, Y. Hayashi, H. Horie, S. Kawauchi, A. Matsumoto, Y. Iwase, Y. Sakamoto, A. Miyaji, K. Motokura, T. Baba, Phys. Chem. Chem. Phys. 12 (2010) 2541-2554. 
Table 1 Physicochemical properties of catalysts used in this work.

\begin{tabular}{cccc}
\hline $\begin{array}{c}\text { Catalyst } \\
(\mathrm{Si} / \mathrm{Al})\end{array}$ & $\begin{array}{c}\text { Specific surface area }^{b} \\
/ \mathrm{m}^{2} \mathrm{~g}^{-1}\end{array}$ & $\begin{array}{c}\text { Micropore volume }^{c} \\
/ \mathrm{cm}^{3} \mathrm{~g}^{-1}\end{array}$ & $\begin{array}{c}\text { Number of acid sites } \\
\\
/ \mathrm{mmol} \mathrm{g}^{-1}\end{array}$ \\
\hline MCM-68(10) & 492 & 0.181 & 0.41 \\
MCM-68(47) & 495 & 0.185 & 0.23 \\
MCM-68(69) & 492 & 0.181 & 0.16 \\
MCM-68(134) & 516 & 0.186 & 0.08 \\
MCM-68(159) & 519 & 0.183 & 0.07 \\
MCM-68(167) & 553 & 0.186 & 0.06 \\
MCM-68(215) & 533 & 0.188 & 0.05 \\
MCM-68(308) & 519 & 0.182 & 0.03 \\
ZSM-5(153) & 374 & 0.160 & 0.07 \\
\hline
\end{tabular}

$a$ Values in parentheses are $\mathrm{Si} / \mathrm{Al}$ ratios determined by ICP-AES analysis.

$b$ Specific surface areas of the catalysts were calculated from the adsorption isotherms by the Brunauer-Emmett-Teller (BET) equation.

$c$ Micropore volumes of the catalysts were calculated from the adsorption isotherm by the $t$-plot method.

$d$ The number of acid sites was determined from the area of $h$-peak in $\mathrm{NH}_{3}$-TPD profiles of catalysts with TCD detector. 
Table 2

DTO reactions over MCM-68 with various $\mathrm{Si} / \mathrm{Al}$ ratios and ZSM-5 zeolite (time on stream = 125 $\min ){ }^{a}$

\begin{tabular}{|c|c|c|c|c|c|c|c|c|c|c|c|c|c|}
\hline \multirow{2}{*}{$\begin{array}{c}\text { Catalyst }^{b} \\
\text { [Si/Al] }\end{array}$} & \multirow{2}{*}{$\begin{array}{c}\text { Conv. }^{c} \\
{[\%]}\end{array}$} & \multicolumn{9}{|c|}{ Product yield $^{d}[\mathrm{C}-\%]$} & \multirow{2}{*}{$\begin{array}{l}\text { M.B. } \\
\text { /C-\% }\end{array}$} & \multirow{2}{*}{$\mathrm{P} / \mathrm{E}^{f}$} & \multirow{2}{*}{$\begin{array}{c}\text { Content } \\
\text { of coke }{ }^{g} \\
{[\mathrm{mg} \text {-coke }} \\
\left.\text { g-cat }{ }^{-1}\right]\end{array}$} \\
\hline & & $\mathrm{MeOH}$ & $\mathrm{C} 1+\mathrm{C} 2+\mathrm{C} 3$ & $\mathrm{C} 2=$ & $\mathrm{C} 3=$ & $\mathrm{C} 4$ & $\mathrm{C} 4=$ & $\mathrm{C} 5+\mathrm{C} 5=$ & $\geq \mathrm{C} 6$ & aromatics & & & \\
\hline MCM-68(10) & 100 & 0 & 16.8 & 6.5 & 3.2 & 18.4 & 0.6 & 4.6 & 31.4 & 5.5 & 86.9 & 0.5 & 65.2 \\
\hline MCM-68(47) & 100 & 0 & 13.0 & 7.1 & 13.9 & 20.5 & 3.9 & 5.9 & 11.3 & 2.1 & 77.7 & 2.0 & 43.8 \\
\hline MCM-68(69) & 100 & 0 & 7.1 & 5.8 & 21.1 & 19.9 & 7.8 & 8.0 & 23.9 & 6.3 & 98.1 & 3.6 & 40.4 \\
\hline MCM-68(134) & 98.2 & $<0.1$ & 0.8 & 1.2 & 37.0 & 5.5 & 22.4 & 10.7 & 15.8 & 2.1 & 97.6 & 31.3 & 24.4 \\
\hline MCM-68(159) & 96.3 & 4.4 & 0.6 & 1.0 & 33.5 & 3.0 & 22.3 & 11.1 & 13.5 & 0.7 & 93.7 & 33.4 & 27.3 \\
\hline MCM-68(215) & 98.0 & 2.0 & 0.8 & 1.1 & 36.6 & 4.7 & 23.0 & 11.3 & 18.7 & 1.2 & 101.2 & 34.8 & 20.5 \\
\hline MCM-68(308) & 94.5 & 3.9 & 0.6 & 1.0 & 28.6 & 3.9 & 18.5 & 9.4 & 14.1 & 0.6 & 85.6 & 29.4 & 30.7 \\
\hline ZSM-5(153) & 99.7 & 0.5 & 1.1 & 4.6 & 36.0 & 6.4 & 18.1 & 12.6 & 16.4 & 4.4 & 97.6 & 7.9 & 1.1 \\
\hline
\end{tabular}

$a$ Reaction conditions: catalyst weight, $100 \mathrm{mg} ; \mathrm{W} / \mathrm{F}=20.0 \mathrm{~g}$-cat h mol ${ }^{-1}$; pellet size, $500-600 \mu \mathrm{m}$; He gas flow rate, 40 $\mathrm{cm}^{3}$ (N.T.P.) $\mathrm{min}^{-1}$; partial pressure of DME $=4.9 \mathrm{kPa}$; reaction temperature, $400{ }^{\circ} \mathrm{C}$. Pretreatment conditions: $550{ }^{\circ} \mathrm{C}, 1$ h, air flow rate, $40 \mathrm{~cm}^{3}$ (N.T.P.) $\mathrm{min}^{-1}$.

$b$ Values in parentheses are $\mathrm{Si} / \mathrm{Al}$ ratios determined by ICP-AES analysis.

$c$ DME conversion $=\left\{1-\left(\mathrm{C}\right.\right.$-atoms of $\left.\mathrm{DME}_{\text {output }}\right) /\left(\mathrm{C}\right.$-atoms of $\left.\left.\mathrm{DME}_{\text {input }}\right)\right\} \times 100$.

$d$ Product yield $=\{(\mathrm{C}$-atoms of the product $) /(\mathrm{C}$-atoms of DMEinput $-\mathrm{C}$-atoms of DMEoutput $)\} \times\{(\mathrm{DME}$ conv. $(\mathrm{C}-\%)\}$.

$e$ Material balance $=\left(\right.$ Total $\mathrm{C}$-atoms of products and $\left.\mathrm{DME}_{\text {output }}\right) /\left(\mathrm{C}\right.$-atoms of $\left.\mathrm{DME}_{\text {input }}\right) \times 100$.

$f$ Propylene-to-ethylene molar ratio in the products.

$g$ Catalysts used in DTO reaction for 305 min were analyzed by thermogravimetry. The weight loss observed from 300 to

$700{ }^{\circ} \mathrm{C}$ in a thermogravimetirc analysis was ascribed to coke. 
Table 3 Product selectivity in DTO reactions over zeolite catalysts. (time on stream $=125 \mathrm{~min}){ }^{a}$

\begin{tabular}{|c|c|c|c|c|c|c|c|c|c|c|c|c|c|c|}
\hline \multirow{2}{*}{$\begin{array}{c}\text { Catalyst }^{b, c} \\
\text { [Si/Al] }\end{array}$} & \multirow{2}{*}{$\begin{array}{c}\mathrm{W} / \mathrm{F} \\
{[\mathrm{g}-\mathrm{cat} \mathrm{h}} \\
\left.\mathrm{mol}^{-1}\right]\end{array}$} & \multirow{2}{*}{$\begin{array}{l}\text { Conv. } \\
\text { [\%] }\end{array}$} & \multicolumn{9}{|c|}{ Selectivity [C-\%] } & \multirow{2}{*}{$\begin{array}{l}\text { M.B. }{ }^{d} \\
{[\mathrm{C}-\%]}\end{array}$} & \multirow[t]{2}{*}{$\mathrm{P} / \mathrm{E}^{e}$} & \multirow{2}{*}{$\begin{array}{c}\text { Content } \\
\text { of coke } \\
{\left[\mathrm{mg}-{ }^{g} \text { coke }\right.} \\
\left.\text { g-cat }^{-1}\right]\end{array}$} \\
\hline & & & $\mathrm{MeOH}$ & $\mathrm{C} 1+\mathrm{C} 2+\mathrm{C} 3$ & $\mathrm{C} 2=$ & $\mathrm{C} 3=$ & $\mathrm{C} 4$ & $\mathrm{C} 4=$ & $\mathrm{C} 5+\mathrm{C} 5=$ & $\geq \mathrm{C} 6$ & aromatics & & & \\
\hline MCM-68(69) & 10 & 99.8 & 0.8 & 3.4 & 4.2 & 30.8 & 11.8 & 13.5 & 9.2 & 22.1 & 4.2 & 86.4 & 7.4 & 50.3 \\
\hline MCM-68(134) & 25 & 99.9 & 0.0 & 1.1 & 1.9 & 37.9 & 6.8 & 21.8 & 10.7 & 17.9 & 1.9 & 104 & 20.3 & 30.7 \\
\hline MCM-68(167) & 30 & 99.6 & 0.5 & 0.9 & 1.4 & 40.9 & 3.7 & 25.0 & 12.4 & 13.3 & 1.4 & 99.8 & 30.2 & 29.0 \\
\hline ZSM-5(153) & 20 & 99.7 & 0.5 & 1.1 & 4.6 & 36.0 & 6.4 & 18.1 & 12.6 & 16.4 & 4.4 & 97.6 & 7.9 & 1.1 \\
\hline
\end{tabular}

$a$ Reaction conditions: catalyst weight, $100 \mathrm{mg}$; pellet size, 500-600 $\mu \mathrm{m}$; He gas flow rate, $40 \mathrm{~cm}^{3}$ (N.T.P.) $\mathrm{min}^{-1}$; partial pressure of $\mathrm{DME}=4.9 \mathrm{kPa}$, reaction temperature, $400{ }^{\circ} \mathrm{C}$.

$b$ Values in parentheses are $\mathrm{Si} / \mathrm{Al}$ ratios determined by ICP-AES analysis.

$c$ Pretreatment conditions: $550{ }^{\circ} \mathrm{C}, 1 \mathrm{~h}$, air flow rate, $40 \mathrm{~cm}^{3}$ (N.T.P.) $\mathrm{min}^{-1}$.

$d$ Material balance $=\left(\right.$ Total $\mathrm{C}$-atoms of products and $\left.\mathrm{DME}_{\text {output }}\right) /\left(\mathrm{C}\right.$-atoms of $\left.\mathrm{DME}_{\text {input }}\right) \times 100$.

$e$ Propylene-to-ethylene molar ratio in the products. 


\section{Figure Captions}

Fig. 1. XRD patterns of (a) MCM-68(10), (b) MCM-68(47), (c) MCM-68(69), (d) MCM-68(134), (e) MCM-68(159), (f) MCM-68(167), (g) MCM-68(215), and (h) MCM-68(308). The number in parentheses means $\mathrm{Si} / \mathrm{Al}$ molar ratio.

Fig. 2. Typical SEM images of (a) MCM-68(10), (b) MCM-68(69), (c) MCM-68(215), and (d) MCM-68(308). The number in parentheses means $\mathrm{Si} / \mathrm{Al}$ molar ratio.

Fig. 3. The conversion of TIPB and cumene cracking at $300^{\circ} \mathrm{C}$ over (O) MCM-68(10) and (•) MCM-68(167). The number in parentheses means Si/Al molar ratio. Conditions: catalyst, 20 $\mathrm{mg}$; He gas flow rate, $30 \mathrm{~cm}^{3}$ (N.T.P.) $\mathrm{min}^{-1}$; dosage, $0.6 \mu \mathrm{L}$ of TIPB from 1 st to 8 th pulses and $0.8 \mu \mathrm{L}$ of cumene from 9 th to 12 th pulses.

Fig. 4. FT-IR spectra of (A) MCM-68(10) and (B) MCM-68(47) after pyridine adsorption $\left(2.7 \mathrm{kPa}, 100^{\circ} \mathrm{C}\right)$ followed by evacuation at various temperatures. While increasing temperature, the spectra were recorded at (a) $150^{\circ} \mathrm{C}$, (b) $200^{\circ} \mathrm{C}$, (c) $250^{\circ} \mathrm{C}$, (d) $300^{\circ} \mathrm{C}$, (e) $350^{\circ} \mathrm{C}$, (f) $400^{\circ} \mathrm{C}$, and (g) $450^{\circ} \mathrm{C}$. More detailed procedure is described in the text (Section 2.2). The peaks $B$ and $L$ are due to pyridines adsorbed on a Brønsted acid site and a Lewis acid site, respectively.

Fig. 5. Relative peak areas of pyridine adsorbed on (A) Brønsted acid sites and (B) Lewis acid sites as a function of cell temperature during FT-IR measurements. Filled symbols represent the relative peak areas over parent MCM-68(10) and open symbols represent those over dealuminated MCM-68(47).

Fig. 6. The effect of reaction temperature on product yields and DME conversions over MCM-68(159) zeolite at (a) $400{ }^{\circ} \mathrm{C}$, (b) $430{ }^{\circ} \mathrm{C}$, (c) $470{ }^{\circ} \mathrm{C}$ and (d) $500{ }^{\circ} \mathrm{C}$, and over ZSM-5(153) at (e) $400{ }^{\circ} \mathrm{C}$ and (f) $500{ }^{\circ} \mathrm{C}$. The number in parentheses means Si/Al molar ratio.

Fig. 7. Effect of reaction temperature on $\mathrm{P} / \mathrm{E}$ molar ratio in the products over (a) MCM-68(159) and (b) ZSM-5(153). The number in parentheses means Si/Al molar ratio. 


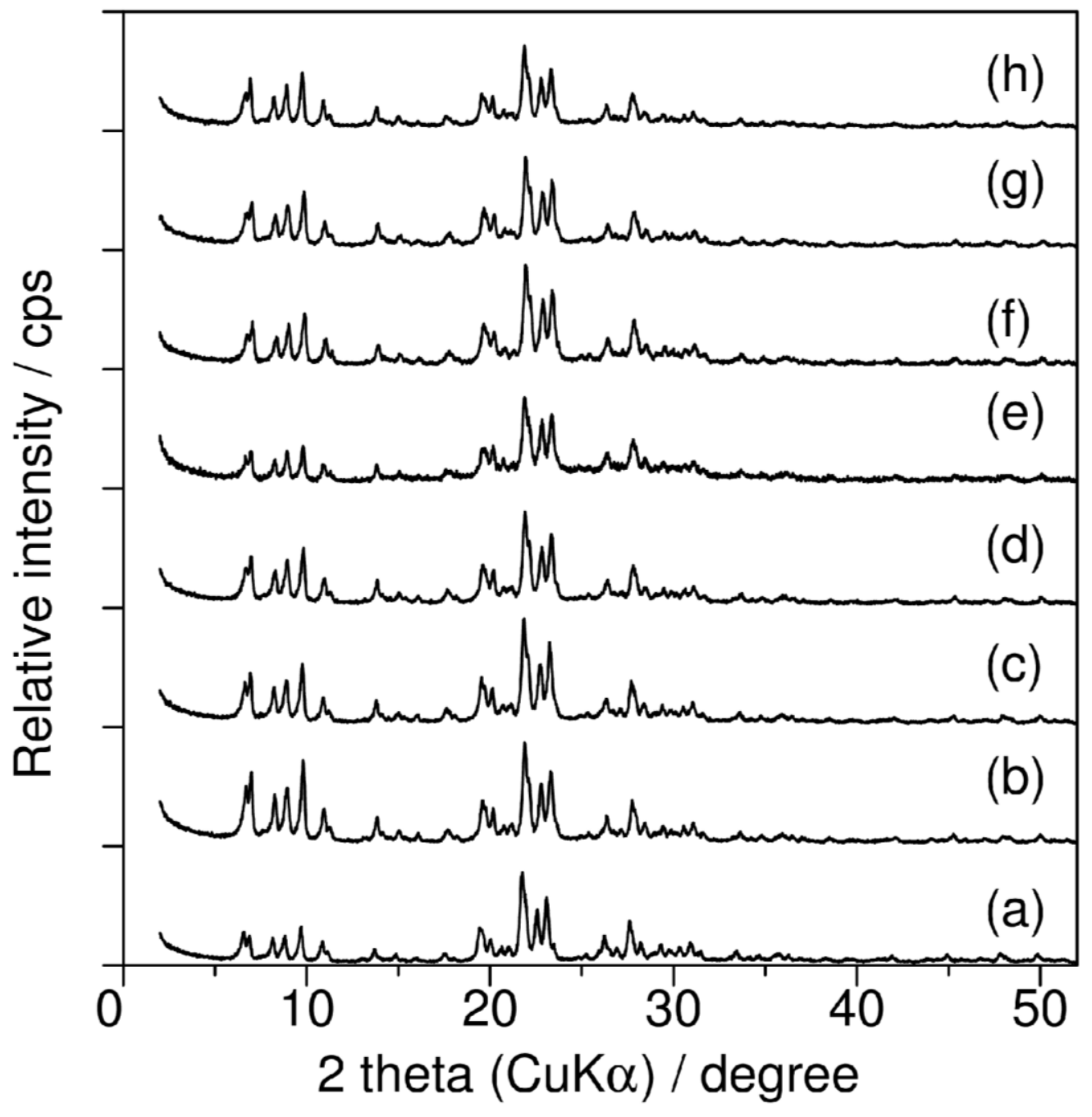

Fig. 1.

XRD patterns of (a) MCM-68(10), (b) MCM-68(47), (c) MCM-68(69), (d) MCM-68(134), (e) MCM-68(159), (f) MCM-68(167), (g) MCM-68(215), and (h) MCM-68(308). The number in parentheses means $\mathrm{Si} / \mathrm{Al}$ molar ratio. 
(a)

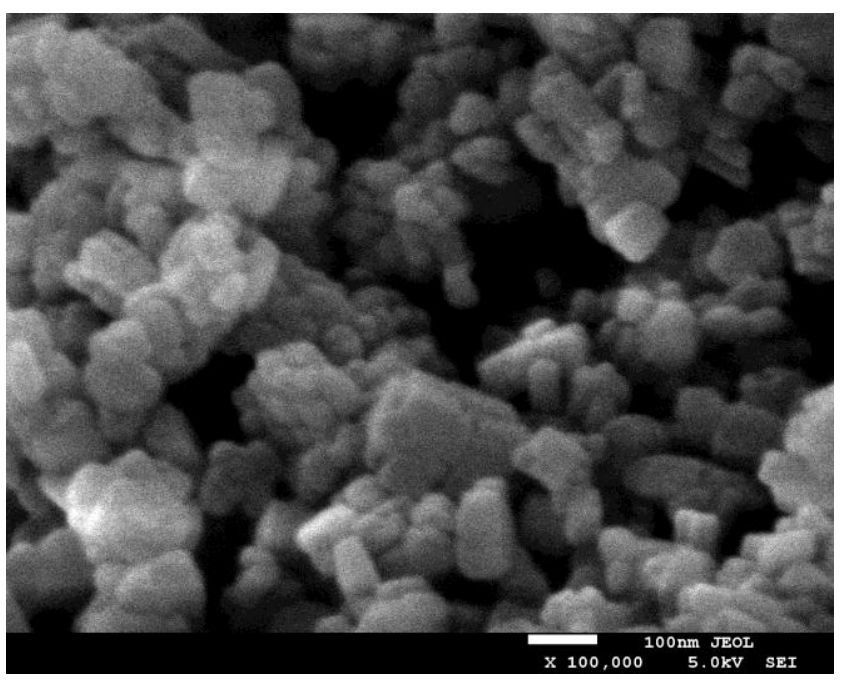

$100 \mathrm{~nm}$

(c)

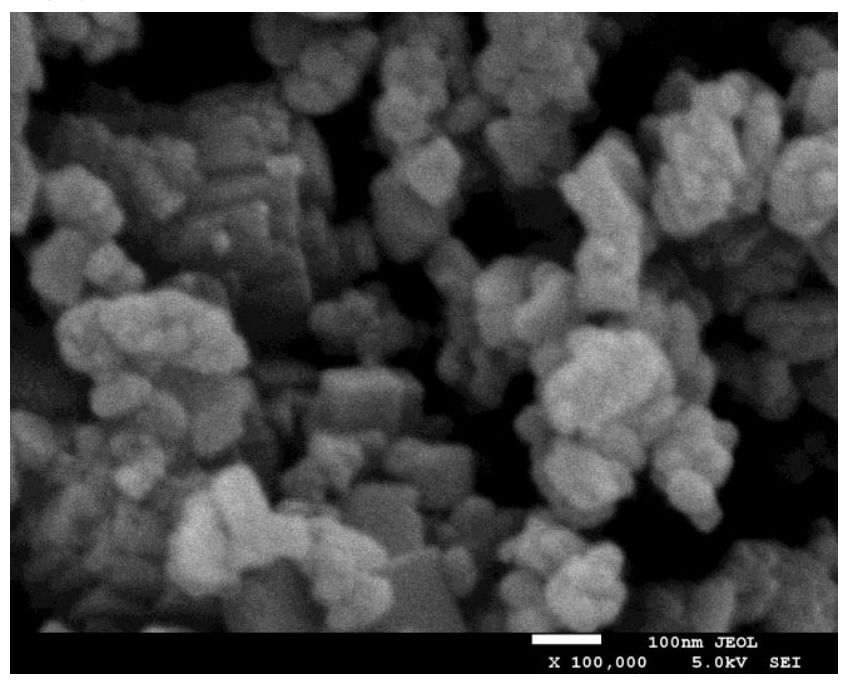

$100 \mathrm{~nm}$ (b)

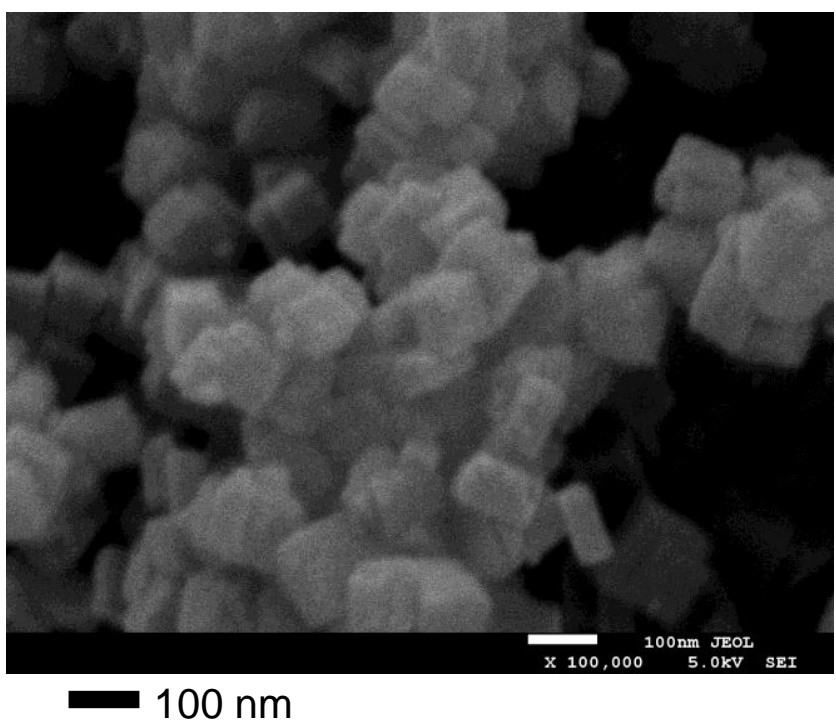

(d)

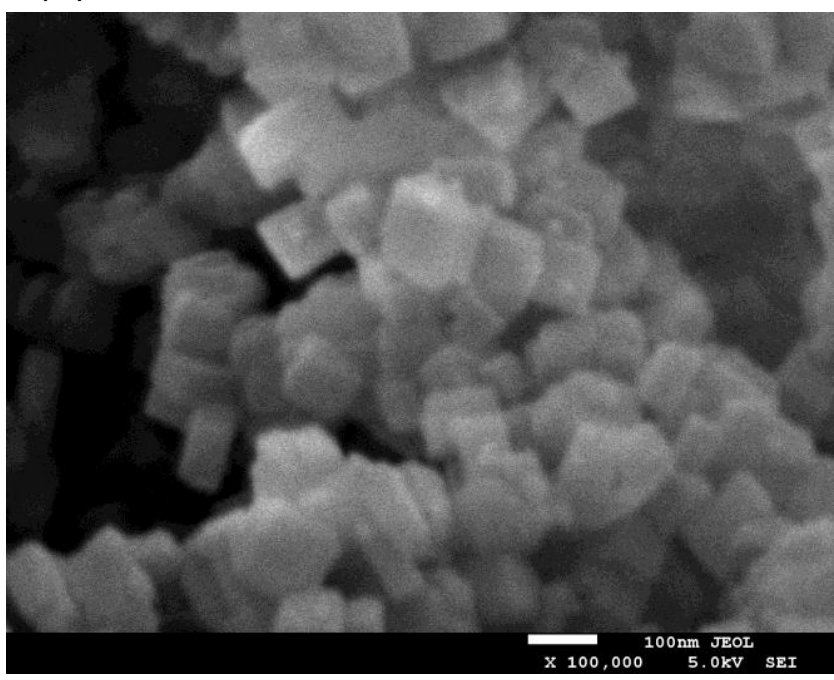

$100 \mathrm{~nm}$

Fig. 2.

Typical SEM images of (a) MCM-68(10), (b) MCM-68(69), (c) MCM-68(215), and (d) MCM-68(308). The number in parentheses means Si/Al molar ratio. 


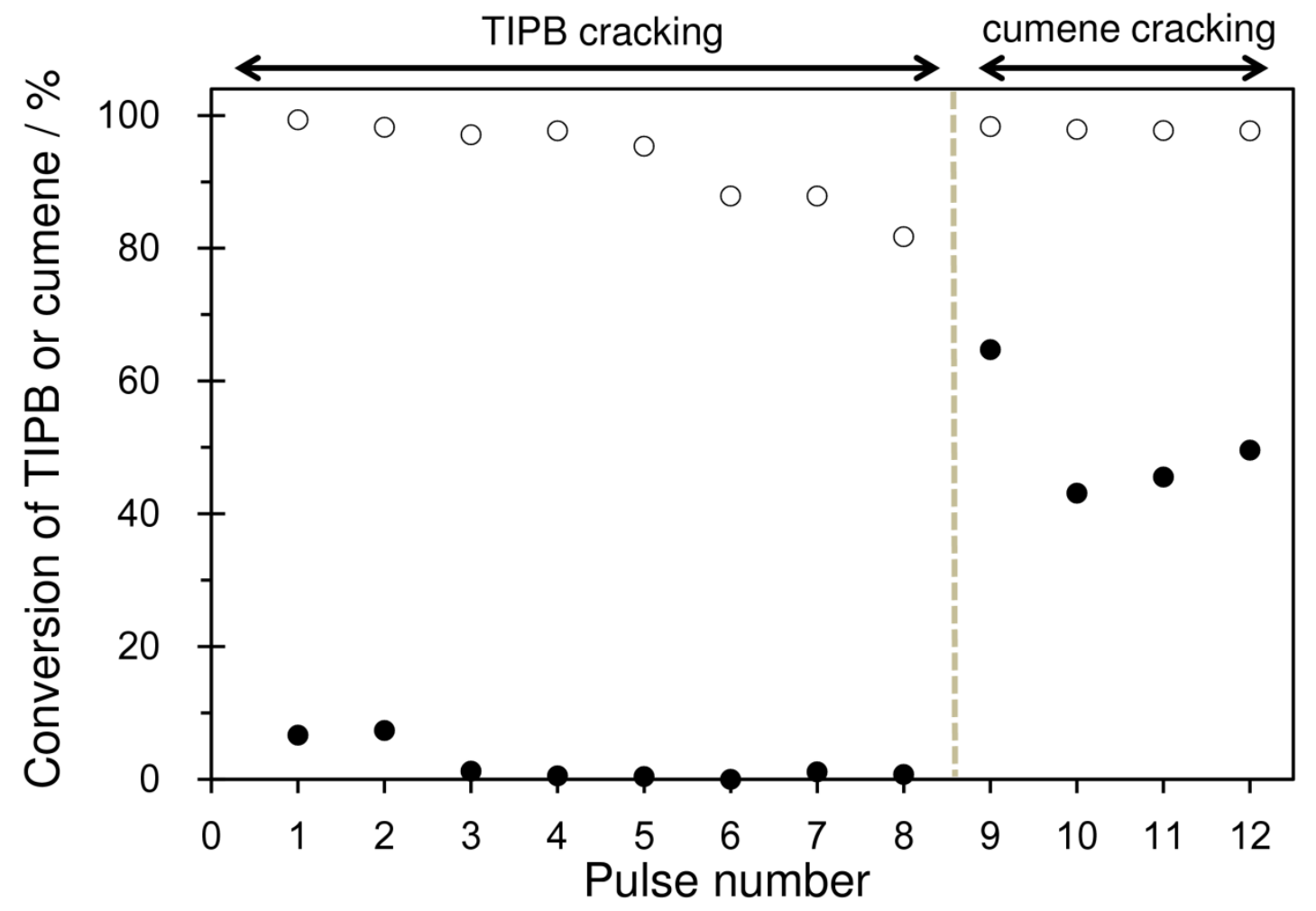

Fig. 3.

The conversion of TIPB and cumene cracking at $300^{\circ} \mathrm{C}$ over (०) MCM-68(10) and (•) MCM-68(167). The number in parentheses means Si/Al molar ratio. Conditions: catalyst, 20 $\mathrm{mg}$; He gas flow rate, $30 \mathrm{~cm}^{3}$ (N.T.P.) $\mathrm{min}^{-1}$; dosage, $0.6 \mu \mathrm{L}$ of TIPB from 1 st to 8 th pulses and $0.8 \mu \mathrm{L}$ of cumene from 9 th to 12 th pulses. 


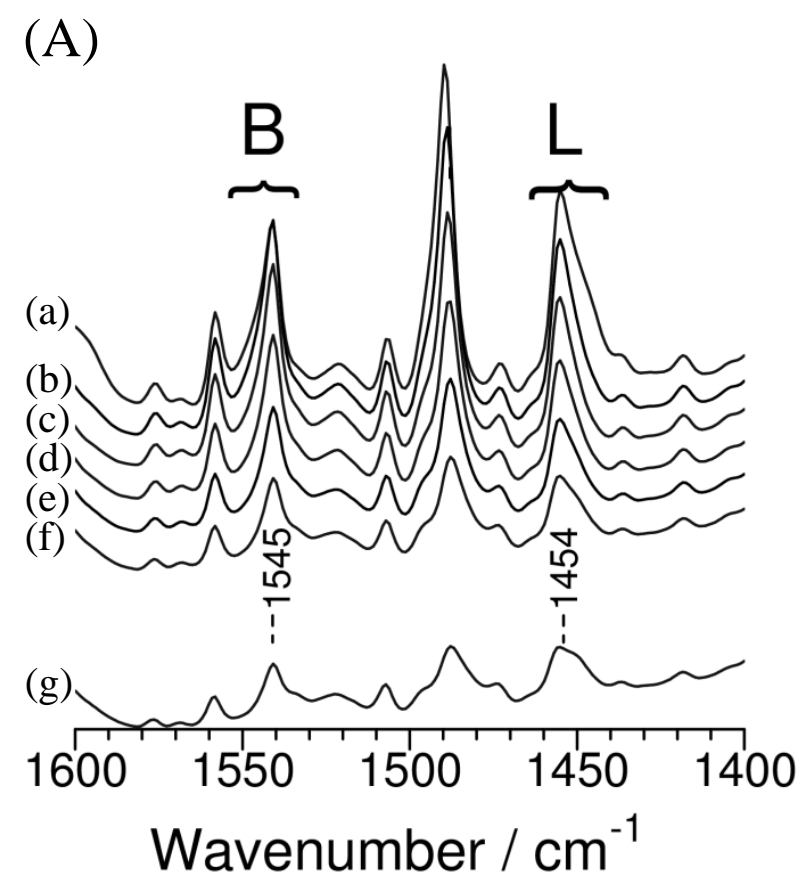

(B)

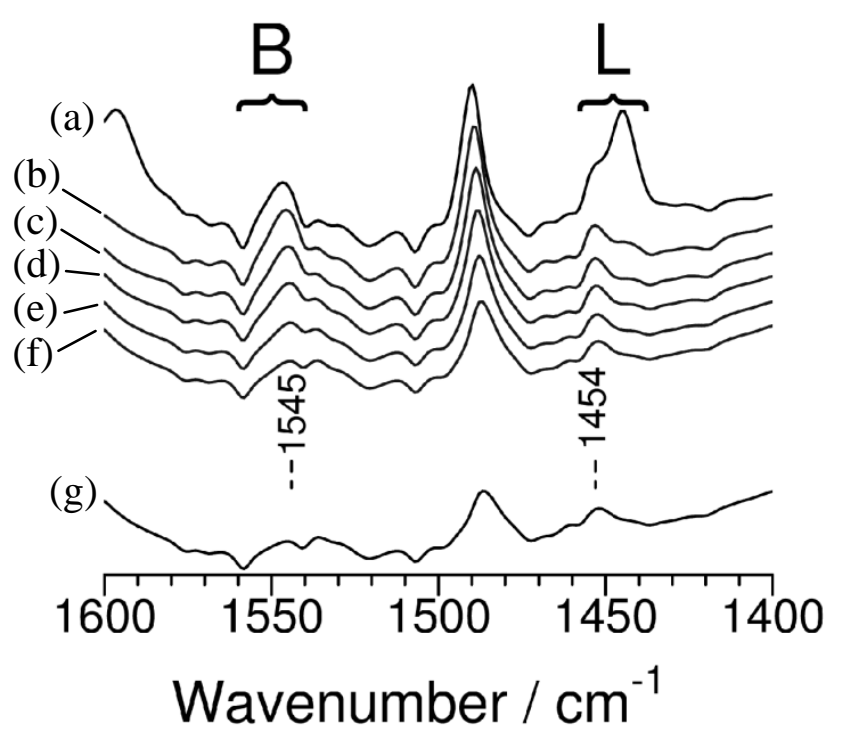

Fig. 4.

FT-IR spectra of (A) MCM-68(10) and (B) MCM-68(47) after pyridine adsorption (2.7 kPa, $100^{\circ} \mathrm{C}$ ) followed by evacuation at various temperatures. While increasing temperature, the spectra were recorded at (a) $150^{\circ} \mathrm{C}$, (b) $200^{\circ} \mathrm{C}$, (c) $250^{\circ} \mathrm{C}$, (d) $300^{\circ} \mathrm{C}$, (e) $350^{\circ} \mathrm{C}$, (f) $400^{\circ} \mathrm{C}$, and (g) $450^{\circ} \mathrm{C}$. More detailed procedure is described in the text (Section 2.2). The peaks B and $\mathrm{L}$ are due to pyridines adsorbed on a Brønsted acid site and a Lewis acid site, respectively. 
(A)

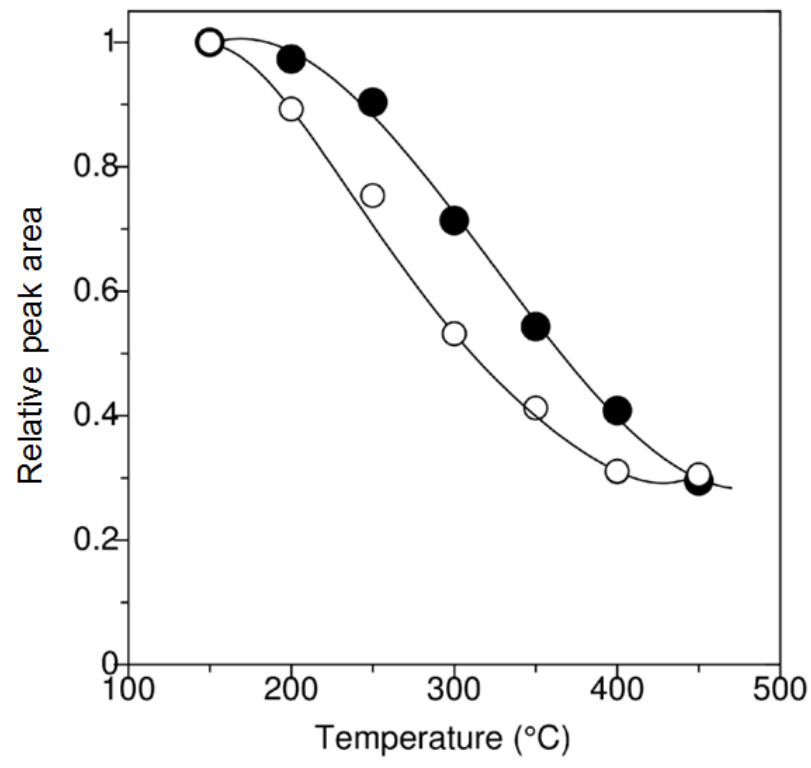

(B)

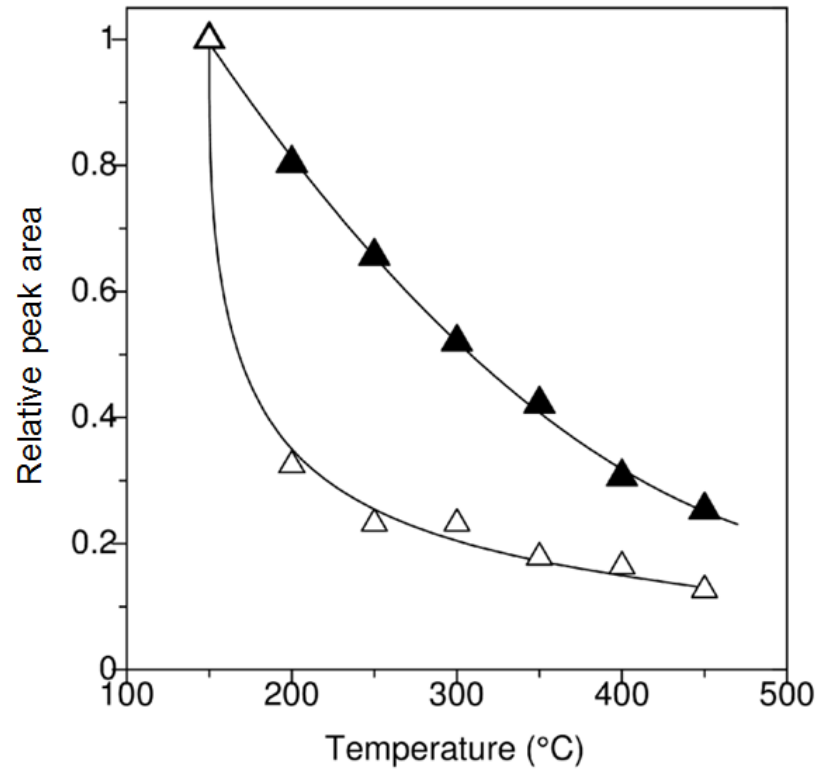

Fig. 5.

Relative peak areas of pyridine adsorbed on (A) Brønsted acid sites and (B) Lewis acid sites as a function of cell temperature during FT-IR measurements. Filled symbols represent the relative peak areas over parent MCM-68(10) and open symbols represent those over dealuminated MCM-68(47). 


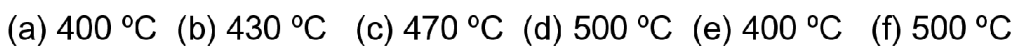

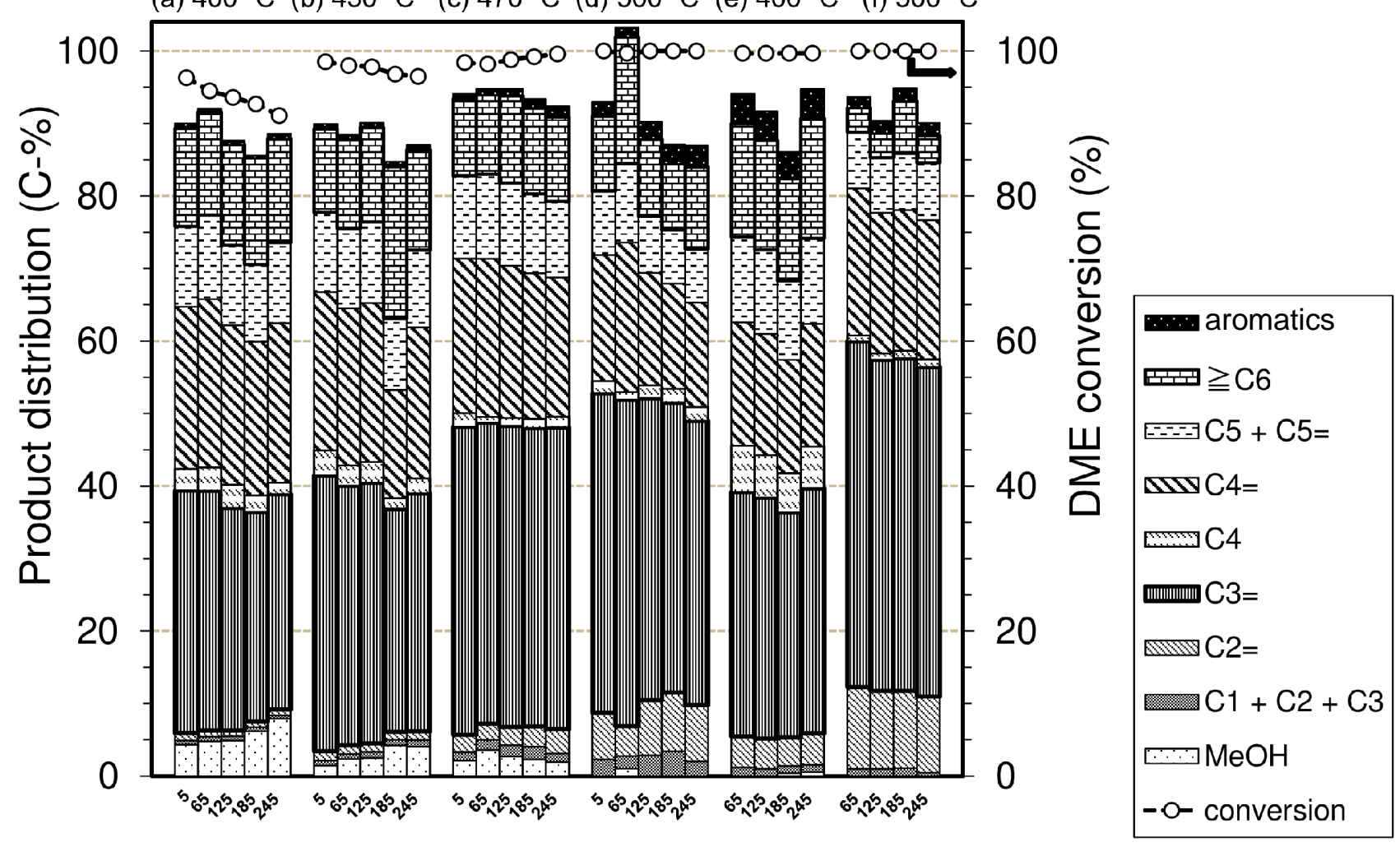

Time on stream (min)

Fig. 6.

The effect of reaction temperature on product yields and DME conversions over MCM-68(159) zeolite at (a) $400{ }^{\circ} \mathrm{C}$, (b) $430{ }^{\circ} \mathrm{C}$, (c) $470{ }^{\circ} \mathrm{C}$ and (d) $500{ }^{\circ} \mathrm{C}$, and over ZSM-5(153) at (e) $400{ }^{\circ} \mathrm{C}$ and (f) $500{ }^{\circ} \mathrm{C}$. The number in parentheses means $\mathrm{Si} / \mathrm{Al}$ molar ratio. 


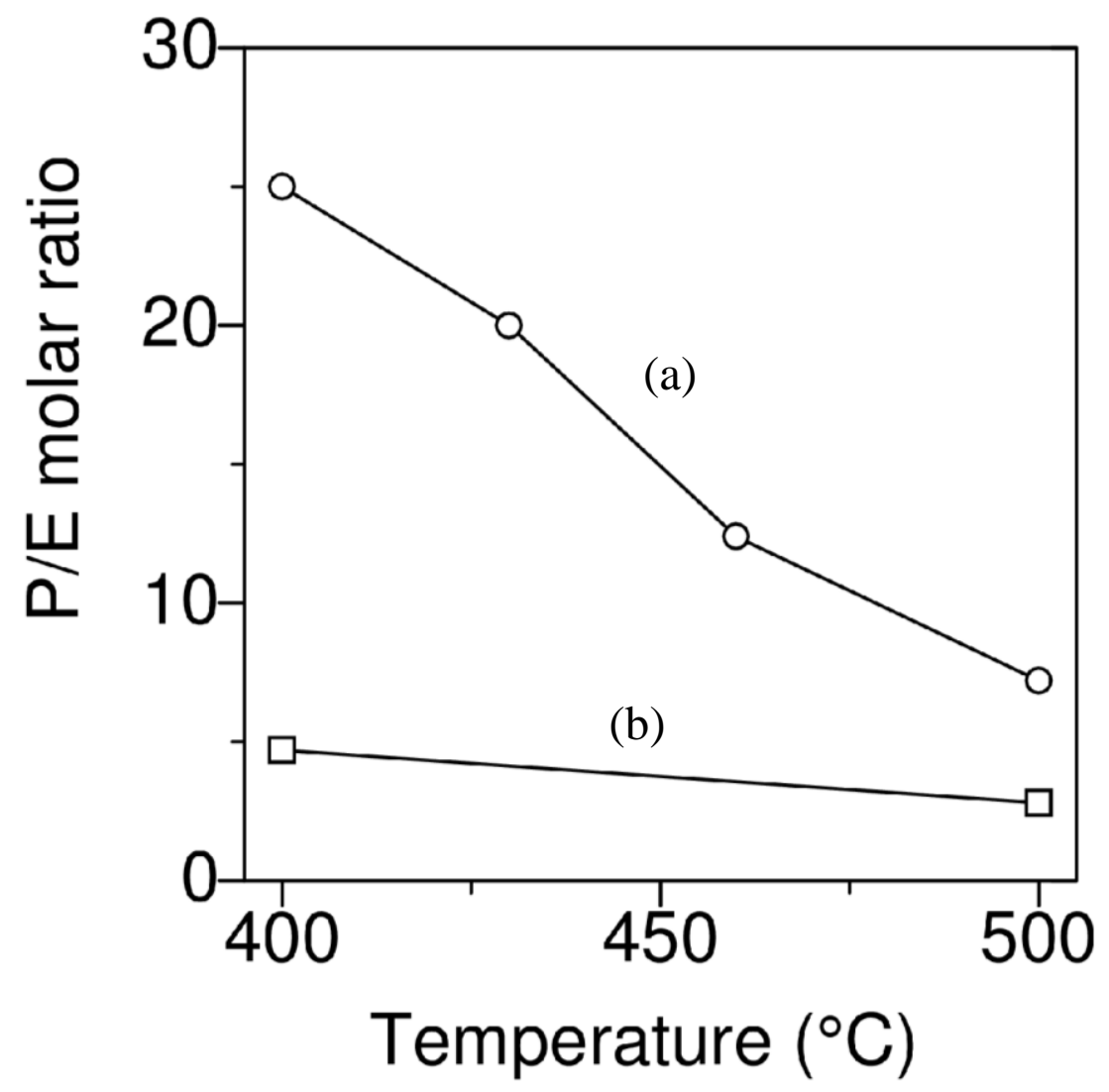

Fig. 7.

Effect of reaction temperature on P/E molar ratio in the products over (a) MCM-68(159) and (b) ZSM-5(153). The number in parentheses means Si/Al molar ratio. 


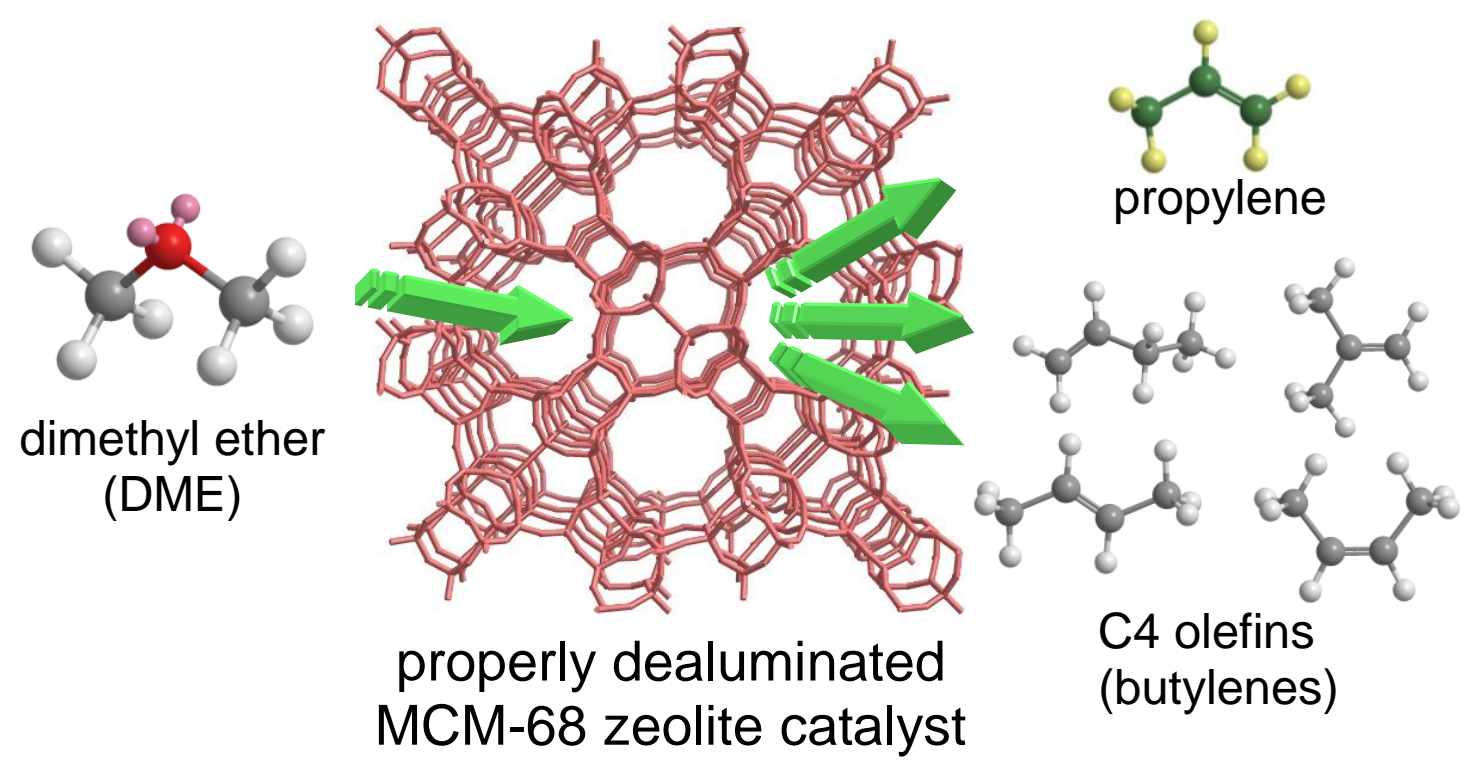

